\title{
Two to Nine Year Review of Breast Conservation Therapy (BCT) for Breast Carcinoma: Clinico-Pathological Features and Outcomes in a Single Centre in East Africa
}

\author{
George I0 Orerah* \\ General surgery, Kenya \\ Received: 制: December 08, 2018; Published: 制: January 04, 2019 \\ *Corresponding author: George IO Orerah, General surgery, Kenya
}

\section{Abstract}

Introduction: Breast conservation therapy compares to mastectomy in terms of overall survival and disease-free survival. However it's utilization in most parts of the sub-Sahara Africa is minimal with various factors cited: patient preference, provider preference and limited access to radiation therapy. The aim of this study was to determine the clinico-pathological profile and outcomes of breast cancer patients treated with breast conservation therapy or mastectomy at a single referral center.

Methods: We retrospectively analysed the details of breast cancer patients who underwent breast conservation therapy from the year 2008 to 2015 and compared this with patients who had undergone mastectomy during the same period at the Aga Khan University hospital.

Results: Ninety - one patients who had breast conservation therapy and 187 patients who underwent mastectomy were included in this study. The majority of patients, $38.1 \%(\mathrm{n}=106)$ had stage II breast cancer. Although there was no stage to stage comparison between the breast conservation group and the mastectomy group, patients who had breast conservation were likely to be younger, with tumor grade I or III and luminal A molecular subtype. There was no significant correlation with being nulliparous, grade II tumor, having received neoadjuvant chemotherapy or re-excision rates. Patients who had mastectomy were likely to be older with grade II breast cancer and had adjuvant chemotherapy.

Conclusion: The present study concluded that with proper pre-operative patient selection, breast conservation therapy has comparable clinicopathological characteristics and outcomes to mastectomy.

Abbreviations: AJCC: American Joint Committee on Cancer; AKU: The Aga Khan University; AKUHN: The Aga Khan University Hospital, Nairobi; BCS: Breast Conservation Surgery; BCT: Breast Conservation Therapy; CITI: Collaborative Institutional Training Initiative; DFS: Disease Free Survival; EORTC: European Organization for Research and Treatment of Cancer; GLOBOCAN: Global Burden of Cancer study; LRFS: Local Recurrence Free Survival; MRM: Modified Radical Mastectomy; NCI: National Cancer Institute; NSABP: National Surgical Adjuvant Breast and Bowel Project; OS: Overall Survival; TNBC: Triple Negative Breast Cancer; TNM: Tumor Node Metastasis; USA: United States of America; WHO: World Health Organization

\section{Introduction}

Breast cancer is the most commonly diagnosed cancer and the leading cause of cancer death in women world over. In Africa, it accounts for one in four diagnosed cancers and up to $20 \%$ of cancer deaths in women [1-3]. Age-adjusted incidence in non-Hispanic white women in the United States from breast cancer is 127.3 per 100,000 compared to the African-American women's 118.4. However, age-adjusted mortality is higher in the African-American women at 30.8 per 100,000 women when compared to the nonHispanic white women, which is at 22.7 per 100,000 women [4]. It is postulated that breast cancer in third world countries occurs less frequently when compared to the resource-rich countries. However the mortality-to-incidence ratios, is higher in third world countries. For example, case fatality is approximately four times greater in East African women compared to North American women [5]. Most countries in Sub-Saharan Africa do not maintain cancer registries hence limited data. Details of death registration varies from ne $100 \%$ in the World Health Organization (WHO) European Region to less than $10 \%$ in the African Region. Cancer-specific mortality statistics are available for only three countries, Mauritius, Reunion \& South Africa. More than half of African women diagnosed with breast cancer die of the disease [6]. 
Breast cancer being a heterogeneous disease also manifests racial differences in the age, grade, receptor status, stage and even mortality. It has been postulated that higher mortality and lower survival rates among African-American women are because of factors associated with lower socioeconomic status and late stage at diagnosis [7-11]. Poverty, illiteracy, and a lack of health insurance are also associated with lower survival rates $[12,13]$. These racial differences in survival persisted even after adjusting for stage at diagnosis, access to health care, treatment, comorbid illness, marital status, and other pathologic and socio-demographic variables [14-17]. Aggressive tumor characteristics associated with poorer prognosis appear to be more common in African American women and may also contribute to lower survival rates $[18,19]$. By 2010, breast cancer death rates were $41 \%$ higher in African American than white women [4]. These Afro-American statistics may reflect the African female breast cancer patients probably due to their shared ancestry [20-23].

\section{Background of Breast Cancer Treatment}

The history of breast cancer treatment is rich. Leonides championed for a wide margin of excision and excision of localized tumor, foreshadowing the oncological principles of contemporary cancer surgical practice $[24,25]$. Galen, attributing breast cancer to the accumulation of black bile in the blood, suggested that it was a systemic disease [25]. During most of the $20^{\text {th }}$ century William S. Halstead of Johns Hopkins hospital in the United States of America (USA) promoted radical mastectomy (first reported in 1894) and emphasized on removing tissues in one piece to prevent spread [26]. This was the treatment of choice for breast cancer of any stage, regardless of the patient's age, for about 80 years. Patey and Handley from London advocated for modified radical mastectomy which preserved the pectoralis major muscle [27]. A randomized clinical trial to compare radical mastectomy with breast conservation surgery was then approved by the WHO in 1969. The recruitment of patients began at the Milan Cancer Institute in 1973, after the new procedure was standardized, and preliminary data showed that survival rates were equal after radical and breast conserving surgery were published in 1977 and 1981 [28,29]. The above studies provided necessary information that allowed dramatic reductions in the extent of surgery required for local control of breast cancer with decreases in treatment related morbidity that then popularized BCT [30-36] (Table 1).

Table 1: Clinical trials comparing Survival after BCT with mastectomy.

\begin{tabular}{|c|c|c|c|c|c|c|}
\hline & \multirow{2}{*}{ Trial } & \multirow{2}{*}{ Endpoint } & \multicolumn{2}{|c|}{ Overall Survival } & \multicolumn{2}{|c|}{ Disease-Free Survival } \\
\hline & & & BCT & Mastectomy & BCT & Mastectomy \\
\hline 1 & Milan I trial & 20 years & 58.3 & 58.8 & 91.2 & 97.7 \\
\hline 2 & $\begin{array}{c}\text { Institut Gustav } \\
\text { Roussy }\end{array}$ & 15 years & 73 & 65 & 69 & 71 \\
\hline 3 & NSABP B-06 & 20 years & 63 & 59 & 49 & 50 \\
\hline 4 & NCI USA trial & 10 years & 77 & 75 & 72 & 69 \\
\hline 5 & EORTC trial & 20 years & 39.1 & 44.4 & 54 & 58 \\
\hline 6 & $\begin{array}{l}\text { Danish Breast } \\
\text { Cancer Group }\end{array}$ & 6 years & 79 & 82 & 70 & 66 \\
\hline
\end{tabular}

\section{Surgical Treatment of Early Breast Cancer}

Non-metastatic breast cancer includes early stage defined as patients with clinical stage II or below [37]. Generally, patients with respectable breast cancer can undergo BCT or mastectomy with or without reconstruction. BCT refers to excision of the breast tumor with concentric margin of surrounding healthy tissue and overlying skin island that has the biopsy site included and done in a cosmetically acceptable manner [38]. Its goals are to provide the survival equivalent of mastectomy, a cosmetically acceptable breast, and a low rate of recurrence in the treated breast. BCT allows patients with breast cancer to preserve their breast without sacrificing oncologic outcome. There are few absolute contraindications to BCT [39]:
a) First or second trimester pregnancy
b) Multicentric breast cancer.
c) Previous irradiation of the breast.
d) Persistent positive tissue margins after surgery.
e) Connective tissue disorders like scleroderma.

f) Large tumor size to breast ratio is a relative contraindication to BCT.

For such patients an alternative approach is the use of neoadjuvant chemotherapy to downstage the tumor.

The surgical technique for BCT entails a curvilinear incision along the natural skin crease line (Lines of Langer) or an elliptical incision and including the skin ellipse with the specimen. A clear macroscopic margin of about $3 \mathrm{~mm}$ of grossly normal breast tissue around the mass is also observed. The specimen is then labelled and sent to the laboratory for frozen section analysis, the results of which are communicated to the surgeon by phone call. This is reported as either positive or negative. Positive margins are defined as ink on tumor, while negative margins as no ink on tumor. Should the margin status be positive, the surgeon performs re-excision at the same sitting. Sentinel lymph node biopsy is performed on patients with non-palpable nodes or less than 3 sentinel lymph nodes. Patients with palpable axillary lymphadenopathy or 3 or more sentinel nodes, undergo axillary lymph node dissection. Histopathology confirms the definite margin status. Patients with 
positive margins on histology undergo re-excision or mastectomy at a later date. After the surgery, post-operative radiotherapy is then administered. Conversely, mastectomy is indicated for patients who are not candidates for BCT and those who prefer mastectomy. For this an elliptical incision is made to include a previous surgical biopsy site if present.

The incision is usually placed horizontally to include the nipple-areolar complex and extended through the dermis into the subcutaneous adipose tissue to expose the superficial investing fascia of the breast. Superior and inferior flaps are then elevated and dissection continued circumferentially following the superficial fascia to its fusion with the muscular fascia around the anatomic borders of the breast. For Modified Radical Mastectomy (MRM), axillary dissection is performed to level II nodes. Post mastectomy radiotherapy is indicated for patients at high risk for local recurrence, including those with any involved axillary lymph nodes. If the likelihood of post mastectomy radiotherapy is high preoperatively, this may affect the choice of mastectomy type, the choice of the reconstructive approach, and optimal timing of the breast reconstruction (Immediate Versus Delayed). Oncoplastic techniques recently introduced, utilize more cosmetically acceptable incisions like sub-areolar incisions. Established goals of oncoplastic breast conserving surgery are to broaden the indication for breast conservation towards larger tumor, and to improve aesthetic outcomes. There is a growing demand to standardize various aspects of oncoplastic BCS for implementation in clinical research and practice.

\section{The African Perspective}

Most patients in Africa typically present approximately 10 years younger than breast cancer patients of western nations and at advanced stages [20,40-43]. African young women suffer a severe form of the disease in terms of higher grade, late stage at diagnosis and a worse prognosis. A higher prevalence of hormone receptor negative and Triple-Negative Breast Cancers (TNBC) has also been previously reported [40-43]. TNBC subtypes account for $12-20 \%$ of all breast cancer; however, women of African descent tend to have a high incidence of TNBC translating into poorer outcomes [44]. A study by Sayed et al. [45] at the Aga Khan University Hospital, Nairobi (AKUHN), however indicated that the receptor status may be comparable to that in the west, with $72.8 \%$ ER positive breast cancer, $64.8 \%$ being PR positive, HER2 in $17.6 \%$ and TNBC in $20.2 \%$ [45]. The majority of women (over $50 \%$ to $70 \%$ ) present with late stage disease that is not amenable to BCT. This makes mastectomy to be the most common surgical procedure performed $[43,46]$.

The limited availability of in Africa is a major factor contributing to the limited access to BCT in many countries. Even where radiotherapy facilities are available in Africa, very few women are considered candidates for breast conservation despite achieving good response rates to neo-adjuvant chemotherapy for various reasons [26]. Maalej et al. reported that even though half of breast cancer patients present with respectable disease in Tunisia, the breast conservation rate was only $17.6 \%$ and was dependent on the surgeon's preferences [47]. Egyptian women with early stage disease may be considered poor candidates for breast conservation because of high illiteracy rate and compounding cultural influences. These factors do not allow for regular surveillance of patients following breast conservation required to detect early recurrence in the remaining breast tissue [48]. Other factors cited include: patient preference, surgeon preference, fear of breast cancer recurrence, adverse effects of radiation therapy and lack of other modalities of treatment. Despite universal acceptance of BCT as the treatment alternative for early stage breast cancer patients, the utilization of the same has not been realized in most Sub-Saharan countries $[43,46,49,50]$.

\section{The Aga khan University Hospital}

The Aga Khan University Hospital, Nairobi (AKUHN), is a tertiary private teaching hospital that has an active breast clinic that is also dedicated to breast cancer screening, diagnosis and management. We have multiple awareness programs including seminars, breast cancer month that have enabled detection of breast cancer at its early stages. The patient profile comprises urban, literate women with access to information, health insurance and healthcare facilities. The age group most affected by breast cancer is in the 45-49-year range with only about $32.5 \%$ presenting with early disease. Thirty one percent of the patients under 50 years have early disease. This patient population under 50 years make up about $66 \%$ of the breast cancer female patients [51]. BCT is an available option offered to patients who meet its criteria. This has been made possible with the availability of surgeons with experience in oncoplastic techniques, well equipped laboratory with capability of doing frozen section with prompt reporting of the results and radiotherapy services with radio-oncologists. About $20 \%$ of the patients with breast cancer undergo breast conservation. BCT has been practiced at the Aga Khan University Hospital Nairobi (AKUHN) since the year 2008 with over 150 cases up to the year 2015 [52].

In terms of adequacy of excision margins, which is a requisite in BCT, Riogi et al. demonstrated that for breast conservation surgeries done in AKUHN up to $85.7 \%$ were negative and only $14.3 \%$ needed a re-excision or mastectomy [52]. This is comparable to published rates in the western world [53-55].

\section{Justification}

BCT is a novel therapy for breast cancer in East Africa [56,57]. We intend to evaluate the clinico-pathologic features of our breast cancer patients who undergo BCT and how they fare after such treatment in terms of disease-free survival and overall survival. We also intend to compare their clinico-pathological features and outcomes with the patients who undergo MRM. To our knowledge, no studies in the region have been done on BCT clinico-pathological features and outcomes. This is in the background of differences in the molecular subtypes in the African women and the comparatively younger age affected by breast cancer. Compared with data on the incidence and overall burden of the disease, there is a significant paucity of data on breast cancer outcomes including overall survival and disease-free survival comparing breast conservation therapy 
and mastectomy. As such most of our practice is based on evidence outside Africa. The evidence for the implementation of BCT as the alternative treatment for early breast cancer to mastectomy is largely from studies done in the western nations. This is in the background that breast cancer in younger women is characterized by a more aggressive disease [58].

\section{Aim and Objective}

The aim of this study was to describe an institutional experience with BCT in terms of the clinico-pathological features and the outcome after such treatment.

\section{Primary Objective}

To determine the clinico-pathological features, disease free survival and overall survival of breast cancer patients who had undergone BCT between 2008 and 2015 at AKUHN.

\section{Secondary Objective}

To describe BCT and mastectomy in terms of

a) Overall survival and disease-free survival.

b) Stage and grade of breast cancer.

c) The molecular subtypes.

\section{Materials and Methods}

\section{Research Design}

This was a single institution historical cohort study of female patients with breast cancer treated with either breast conservation therapy or modified radical mastectomy. The study employed crosssection retrospective design to collect data from records of women that underwent surgery between the periods: $1^{\text {st }}$ January 2008 to $31^{\text {st }}$ December 2015.

\section{Data Collection and Management}

Data collection was done via retrieval of records of patients who had breast surgery for breast carcinoma at AKUHN between 2008 and 2015. Data was obtained from the hospital's medical records department. Pathology reports were obtained from the hospital's software system 'care2000'. Patients' details were assessed for demographics like age, patient's race and parity; clinical manifestation like breast lump, breast pain, nipple discharge; tumor-related characteristics (tumor size, TNM stage and grade, molecular subtypes), treatment-related characteristics and followup related characteristics. (See Patient Data Capture Sheet: Breast conservation therapy at the AKUHN 2008-2015 and the appendix below). Data on staging were retrieved from the pathology report biopsy specimen, clinical assessment of the admitting physician as recorded in the file or when absent, they were derived by assessing the staging investigations entered in the file. The American Joint Committee on Cancer (AJCC) $7^{\text {th }}$ edition staging system was used [21].

Outcomes of interest were disease free survival and overall survival. Disease-free survival that is loco-regional recurrence or distance recurrence was measured from the date of surgery until recurrence or the follow-up visit at the $2^{\text {nd }}$ and or $9^{\text {th }}$ year whichever came first. Local or regional recurrences was be defined as recurrences in the ipsilateral supraclavicular, axillary, or internal mammary nodal regions; chest-wall disease; or inoperable recurrence within the breast. Recurrence within the breast that was successfully treated by mastectomy was considered a local or regional recurrence. Overall survival was measured from the date of surgery until death or at the $2^{\text {nd }}$ or the $9^{\text {th }}$ year. The timing of censoring was at least 2 years since the last entered patient record was on the $31^{\text {st }}$ December 2015 and the end of the study period was $31^{\text {st }}$ December 2017 . The data collected were entered into a computer using the goggle forms software that is password protected and there-after analysed.

\section{Sample Size}

All eligible candidates were recruited. This included all the breast cancer patients underwent breast conservation therapy between $1^{\text {st } J a n u a r y ~} 2008$ and $31^{\text {st }}$ December 2015.

\section{Inclusion Criteria}

January $1^{\text {st }} 2008$ and December $31^{\text {st }} 2015$.

-IIIA breast cancer.

\section{Exclusion Criteria}

Records of patients with breast cancer of stage IIIB to Stage IV. Bilateral breast cancer by the time of index surgery Previous history of another cancer. Histology not consistent with a solid breast tumor, including sarcoma, pagets disease of the nipple, lymphoma and hematopoietic tumor.

\section{Statistical Analysis}

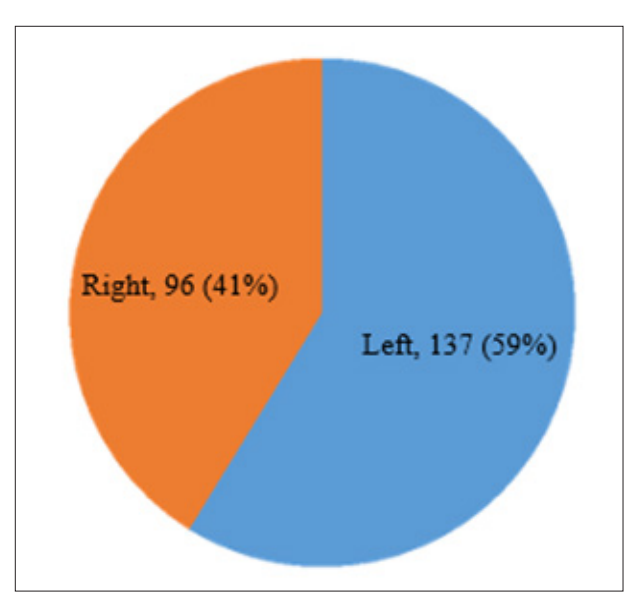

Figure 1: Patients presenting with breast lumps.

Profiling of patient-related characteristics was done. This included age, race, parity, presenting symptoms and laterality. Tumor- related characteristics was also profiled to include the size, nodal status, histologic subtype and receptor status. Treatmentrelated characteristics included neo-adjuvant therapy, adjuvant therapy, resection margins, conversion to mastectomy rates and 
hormonal therapy. Follow-up related characteristics included time to recurrence, number of follow up visits and duration of follow-up. We did not obtain data on mortality and therefore did not analyze mortality rates. Data were collected via a data-sheet form designed for the study (see appendix below) and entered into a spreadsheet program. These were then analysed done using stata version 12

Table 2: Clinical demographic characteristics. and two sample tests of proportion to compare the equality of the proportions. The results (percentages, rates and proportions) were presented in tables and graphs. Data collected were stored in a safe computer with a password only accessible to the principal investigator (Tables 2 \& 3) and (Figure 1).

\begin{tabular}{|c|c|c|c|}
\hline \multirow{2}{*}{ Variables } & \multicolumn{3}{|c|}{ Type of Surgery } \\
\hline & Frequency $(\mathrm{N}=278)$ & BCT $(n=91)$ & Mastectomy $(n=187)$ \\
\hline \multicolumn{4}{|c|}{ Age at Time of Diagnosis } \\
\hline$<35$ & $27(9.7)$ & $10(37.0)$ & $17(63.0)$ \\
\hline $36-50$ & $103(37.1)$ & $37(35.9)$ & $66(64.1)$ \\
\hline$>51$ & $148(53.2)$ & $44(29.7)$ & $104(70.3)$ \\
\hline \multicolumn{4}{|c|}{ Race } \\
\hline African & $242(87.1)$ & $85(35.9)$ & 157 (64.9) \\
\hline Asian & $23(8.3)$ & $3(13.0)$ & $20(87.0)$ \\
\hline Other & $13(4.7)$ & $3(23.1)$ & $10(76.9)$ \\
\hline \multicolumn{4}{|c|}{ Parity } \\
\hline Nulliparous & $12(4.3)$ & $5(41.7)$ & $7(58.3)$ \\
\hline Para 1 & $20(7.2)$ & $3(15.0)$ & $17(85.0)$ \\
\hline Multiparous ( 2 or more) & $60(21.6)$ & $23(38.3)$ & $37(61.7)$ \\
\hline Grand multiparous ( 5 or more) & $19(6.8)$ & $6(31.6)$ & $13(68.4)$ \\
\hline Not specified & $167(60.1)$ & $54(32.3)$ & $113(67.7)$ \\
\hline \multicolumn{4}{|c|}{ Laterality } \\
\hline Left & $164(59.0)$ & $54(32.9)$ & $110(67.1)$ \\
\hline Right & $114(41.0)$ & $37(32.5)$ & $77(67.5)$ \\
\hline \multicolumn{4}{|c|}{ Presenting Symptoms } \\
\hline Breast lump & $233(83.8)$ & $81(34.8)$ & $152(65.2)$ \\
\hline Breast pain & $15(5.4)$ & $4(26.7)$ & $11(73.3)$ \\
\hline Nipple discharge & $5(1.8)$ & $2(40.0)$ & $6(60.0)$ \\
\hline Combination of any two above & $10(3.6)$ & $2(20.0)$ & $8(80.0)$ \\
\hline Other & $15(5.4)$ & $4(26.7)$ & $13(86.7)$ \\
\hline
\end{tabular}

Table 3: Pathological characteristics of patients.

\begin{tabular}{|c|c|c|c|}
\hline Variables & Frequency $(\mathrm{N}=278)$ & BCT $(n=91)$ & Mastectomy $(n=187)$ \\
\hline \multicolumn{4}{|c|}{ Tumor Size } \\
\hline $\mathrm{Tx}$ & $9(3.2)$ & $0(0.0)$ & $9(100.0)$ \\
\hline Tis & $11(4.0)$ & $3(27.3)$ & $8(72.7)$ \\
\hline $\mathrm{T} 1$ & $39(14.0)$ & $12(30.8)$ & $27(69.2)$ \\
\hline $\mathrm{T} 2$ & $129(46.4)$ & $46(35.7)$ & $83(64.3)$ \\
\hline T3 & $39(14.0)$ & $11(28.2)$ & $28(71.8)$ \\
\hline $\mathrm{T} 4$ & $4(1.4)$ & $1(25.0)$ & $3(75.0)$ \\
\hline Not specified & 47 (16.9) & $18(38.3)$ & $29(61.7)$ \\
\hline \multicolumn{4}{|c|}{ Nodal Status } \\
\hline NX & 10 & 3 & $7(70.0)$ \\
\hline No & 92 & 38 & 54 (58.7) \\
\hline $\mathrm{N} 1$ & 69 & 24 & $45(65.2)$ \\
\hline
\end{tabular}

Cite this article: George IO Orerah. Two to Nine Year Review of Breast Conservation Therapy (BCT) for Breast Carcinoma: Clinico-Pathological Features and Outcomes in a Single Centre in East Africa. Biomed J Sci \& Tech Res 12(5)-2019. BJSTR. MS.ID.002313. DOI: 10.26717/ BJSTR.2019.12.002313. 


\begin{tabular}{|c|c|c|c|}
\hline $\mathrm{N} 2$ & 42 & 7 & $35(83.3)$ \\
\hline N3 & 16 & 1 & 15 (93.7) \\
\hline Not specified & 49 & 18 & $31(63.3)$ \\
\hline \multicolumn{4}{|c|}{ Staging Modality } \\
\hline Clinical stage & $2(0.7)$ & $0(0.0)$ & $2(100.0)$ \\
\hline Pathological stage & $273(98.2)$ & $91(33.3)$ & $182(66.7)$ \\
\hline Not specified & $3(1.1)$ & $0(0.0)$ & $3(100.0)$ \\
\hline \multicolumn{4}{|c|}{ Staging Class } \\
\hline Stage 0 & 25 & $3(12.0)$ & $22(88.0)$ \\
\hline Stage 1 & 32 & $10(31.2)$ & $22(68.8)$ \\
\hline stage 2 & 106 & $43(40.6)$ & $63(59.4)$ \\
\hline Stage 3 & 73 & $17(23.3)$ & $56(76.7)$ \\
\hline NA & 40 & $17(42.5)$ & $23(57.5)$ \\
\hline \multicolumn{4}{|c|}{ Histological Subtypes } \\
\hline Invasive ductal carcinoma & 201 & 74 & $127(63.2)$ \\
\hline Invasive lobular carcinoma & 12 & 3 & $9(75.0)$ \\
\hline DCIS & 20 & 2 & $18(90.0)$ \\
\hline Other & 41 & 12 & $29(70.7)$ \\
\hline Not specified & 4 & 0 & $4(100.0)$ \\
\hline \multicolumn{4}{|c|}{ Histological Grade } \\
\hline Grade 1 & $43(15.5)$ & $13(30.2)$ & $30(69.7)$ \\
\hline Grade 2 & $134(48.2)$ & $40(29.8)$ & $94(70.2)$ \\
\hline Grade 3 & $86(30.9)$ & $36(41.9)$ & $50(58.1)$ \\
\hline Not specified & $15(5.4)$ & $2(13.3)$ & $13(86.7)$ \\
\hline \multicolumn{4}{|c|}{ Receptor Status } \\
\hline Luminal A & 5 & 112 & $166(59.7)$ \\
\hline Luminal B & 4 & 3 & $7(2.5)$ \\
\hline Triple negative & 1 & 3 & $4(1.4)$ \\
\hline HER2/neu positive & 5 & 9 & $14(5.0)$ \\
\hline Not specified & 27 & 60 & 87 (31.3) \\
\hline \multicolumn{4}{|c|}{ Neo-Adjuvant Chemotherapy } \\
\hline Yes & $82(29.5)$ & $34(41.5)$ & $48(58.5)$ \\
\hline No & $130(46.8)$ & $43(33.1)$ & $87(66.9)$ \\
\hline Not specified & $66(23.7)$ & $14(21.2)$ & $52(78.8)$ \\
\hline \multicolumn{4}{|c|}{ Hormonal Therapy } \\
\hline Yes & $164(59.0)$ & $57(34.8)$ & $107(65.2)$ \\
\hline No & $66(23.7)$ & $18(27.3)$ & $48(72.7)$ \\
\hline Not specified & $48(17.6)$ & $16(33.3)$ & $32(66.7)$ \\
\hline \multicolumn{4}{|c|}{ Adjuvant Chemotherapy } \\
\hline Yes & 195 & $73(37.4)$ & $122(62.6)$ \\
\hline No & 34 & $6(17.7)$ & $28(82.3)$ \\
\hline Not specified & 49 & $12(24.5)$ & $37(75.5)$ \\
\hline \multicolumn{4}{|c|}{ Distance of Closest Resection Margin } \\
\hline $6-10 \mathrm{~mm}$ & $7(2.6)$ & $2(28.6)$ & $5(71.4)$ \\
\hline$<5 \mathrm{~mm}$ & $13(4.8)$ & $5(38.5)$ & $8(61.5)$ \\
\hline$>10 \mathrm{~mm}$ & $189(69.2)$ & $63(33.3)$ & $126(66.7)$ \\
\hline Not specified & $64(23.4)$ & $21(32.5)$ & $43(67.2)$ \\
\hline
\end{tabular}




\section{Discussion}

The Aga Khan University Hospital, Nairobi (AKUHN), is a tertiary private teaching hospital that has an active breast clinic that is also dedicated to breast cancer screening, diagnosis and management. We have multiple awareness programs including seminars, breast cancer month that have enabled detection of breast cancer at its early stages. BCT is an available option offered to patients who meet its criteria and has been practiced at the Aga Khan University Hospital Nairobi (AKUHN) since the year 2008 with over 150 cases up to the year 2015 [52]. In this study, breast conservation therapy was offered to $32.7 \%$ of the breast cancer patients who were eligible for it. Although this is higher than early work done by Riogi and Wasike in which only $21.9 \%$ had BCT [52], it is still lower than what other series report of about $48 \%[61,62]$ (Table 4). This relatively higher utility of BCT can be attributed to the longer study duration and the higher sensitization of BCT. In terms of age, 53.2\% of the patients were over the age of 51 years, which is similar to what Maalej reported in Tunisia [47] and from the global perspective $[63,64]$. Previous study at AKUHN had indicated an average age of 45 years [51,52]. Young-aged breast cancer (less than 35 years) was 9.7\% in our series similar to Korea but higher than in the US and European countries $[65,66]$.

Table 4: Patients outcomes.

\begin{tabular}{|c|c|c|c|}
\hline Variables & Frequency & BCT & Mastectomy \\
\hline \multicolumn{3}{|c|}{ Re-Excision Before Local Recurrence } \\
\hline Yes & $30(10.8)$ & $10(33.3)$ & $20(66.7)$ \\
\hline No & $223(80.2)$ & $75(33.6)$ & $148(66.4)$ \\
\hline Not specified & $25(9.0)$ & $6(24.0)$ & $19(76.0)$ \\
\hline \multicolumn{3}{|c|}{ What was the Second Operation } \\
\hline Mastectomy & $26(86.7)$ & $8(30.8)$ & $2(69.2)$ \\
\hline Repeat wide local excision & $4(13.3)$ & $2(50.0)$ & $2(50.0)$ \\
\hline 3+ years & Time to Recurrence/Distance Metastasis & $2(0.7)$ \\
\hline < years & $0(0.0)$ & $4(40.0)$ & $10(3.6)$ \\
\hline No recurrence & $6(60.0)$ & $178(68.2)$ & $261(93.9)$ \\
\hline Not specified & $0(0.0)$ & $3(100.0)$ & $3(1.1)$ \\
\hline Recurrence & $2(100.0)$ & $0(0.0)$ & $2(0.7)$ \\
\hline
\end{tabular}

When BCT was compared to mastectomy, we found that BCT was popular among the younger patients, mastectomy was commoner as the age increased. The sample population was largely African (87.1\%), likely due to their predominance in this locality. However, this could also be due to the limited number of patients in this study. BCT was offered in up to $36 \%$ of the African which would reflect the relatively higher socioeconomic status of this patient population. This is however anecdotal as we were not able to gather such data due to inadequate record keeping. The Asian race, though relatively common in the hospital's catchment area only contributed to $8.3 \%$. A surprising finding was the relatively lower proportion of breast cancer in the nulliparous women (4.3\%). This was surprising since traditionally this has been a risk factor to breast cancer [20,67-69]. Makanga et al. [51] in his study also found a relatively lower incidence of $16 \%$ of the breast cancer patients to be nulliparous [51]. This however could be attributed to the lower number of patients and the inadequacy of documentation in a retrospective study.

In contrast, multiparous women with 2 to 4 children had the highest frequency of $21.6 \%$. In all categories, more women had mastectomy as compared to BCT. In terms of presentation, painless breast lump was the commonest symptom and predominantly on the left breast. Most of the tumor (46.4\%) had estimated sizes of between 20 to $50 \mathrm{~mm}$. This is similar to what Riogi found at an average size of $23.5 \mathrm{~mm}$ as well as in Maalej study in which the range was between $35.8 \mathrm{~mm}$ and $50.7 \mathrm{~mm}[47,52]$. BCT was offered more to this category of patients' tumor size, while mastectomy was offered more to T3 and T4 tumor. Though absolute size alone is not a criterion to BCS, it likely suggests the suitability of BCS given other factors. Gakinya and colleagues however found the average tumor size to be $5.9 \mathrm{~cm}$ [70]. For the infiltrate's cancers, grade II was the most prevalent (48.2\%), while $30.9 \%$ had grade III disease. Only $15.5 \%$ had grade I breast cancer. Other findings in Africa reflect similar higher-grade breast cancer, with Maalej reporting $53.6 \%$ having grade II breast cancer [47]. Two thirds of the patients had nodal metastasis. Both the BCT and mastectomy arms had majority of the patients having N1 disease and above. The tumor grade and nodal involvement did not influence the type of surgery as demonstrated by other studies [38]. The commonest molecular subtype in this study was luminal A (59.7\%). This is in keeping with other studies done on molecular subtypes in the west $[18,71]$. Gakinya and colleagues however found that the incidence of luminal A breast cancer in an earlier study was $42 \%$ [70], lower than what our study found but still the commonest molecular subtype. HER2/ neu breast cancer was the second commonest with five percent, while luminal B disease was $2.5 \%$ and triple negative breast cancer at $1.4 \%$. The latter was surprisingly lower than what other studies have quoted in earlier studies of about $23 \%[18,70,72]$. Luminal A

Cite this article: George IO Orerah. Two to Nine Year Review of Breast Conservation Therapy (BCT) for Breast Carcinoma: Clinico-Pathological Features and Outcomes in a Single Centre in East Africa. Biomed J Sci \& Tech Res 12(5)-2019. BJSTR. MS.ID.002313. DOI: 10.26717/ BJSTR.2019.12.002313. 
breast cancer was also the commonest molecular subtype across all the age groups and all the stages of breast cancer evaluated in this study.

The staging modality was predominantly pathological. Early stage disease was noted in this with $58.6 \%$ of the patients presenting with stage 0 , I or II disease. Twenty six percent presented with stage III disease. This is contrary to what Makanga et al. had earlier found of only $32.5 \%$ of breast cancer patients having early stage disease [51]. Our findings in this study could be attributed to the earlier diagnosis in this population of patients but also the exclusion of stage IV breast cancer patients and the limited number of patients cannot be underplayed. Calleb et al. demonstrated late stage of presentation at the coast provincial general hospital [73]. Similar findings were obtained by Vorobiof et al. in South Africa and Fregene et al. [20,74]. The proportion of breast cancer patients in which BCS was appropriate was not stage dependent; $4.1 \%(n=3)$ in carcinoma in situ, $14.9 \%(n=11)$ in stage $I, 58.1 \%(n=43)$ in stage II and $22.9 \%(n=17)$ in stage III. This is in contradistinction to what Tyldesley et al. [62] found, though for the suitable BCS patient, higher stage is not a contraindication to the operation. When stage was compared to the age groups, it was found that postmenopausal women (over the age of 50 years), were the majority across all the stages of disease. However, there was no statistical significance noted when stage was compared across the different age groups.

The commonest histologic diagnosis was invasive ductal carcinoma $(72.3 \%)$ which is similar to contemporary populationbased series [52,75]. More than two thirds of the patients in all the categories underwent mastectomy. However, for DCIS in which $90 \%$ of the patients underwent mastectomy with only $10 \%$ undergoing BCT. For neo-adjuvant chemotherapy, only $29.5 \%$ of the patients received this. Of these, $41.5 \%$ underwent BCT. Hormonal therapy was administered to $59 \%$ of the patients. The ones who underwent BCT constituted were 34.8\%. (Compare hormonal therapy with receptor status). Adjuvant chemotherapy was administered to seventy percent of the patients. Of these, $37.4 \%$ had undergone BCT. The distance of closest resection margin was more than $10 \mathrm{~mm}$ in both types of surgeries. In this study positive margins that necessitated re-excision were only $10.8 \%$ This is a slight improvement from the earlier documented positive margin of $15.3 \%$ [52]. Other centers have published excision rates ranging from 13 to $72 \%[54,55,76]$. This could be attributed to our wider margin levels of more than $10 \mathrm{~mm}$ in two thirds of our patients undergoing BCT. Other centers have used margins of even $2 \mathrm{~mm}$ [77]. The majority of our patients who had positive margins $(86.7 \%)$ were treated with mastectomy. Eighty three percent of the patients had no recurrence during the study duration.

\section{Limitations}

This being a retrospective study, the investigator had to retrieve pre-existing data that was not necessarily acquired in a predetermined way and hence inherently susceptible to poor record keeping, lack of standardization and methods of recording. We particularly faced challenges from the private patients where the recording was highly abbreviated and poor follow up was noted. We were not able to estimate disease free survival rates and overall survival rates largely as a result of lack of data on mortality. This could have been due to loss of follow up of our patients or lack of documentation of such. The lack of significant difference to the characteristics analysed may be because of the small sample size used in this study.

\section{Conclusion and Recommendations}

Standardization of patients records especially for cancer diagnosis. This will facilitate future population or hospital-based studies with better precision and accuracy. Follow up of the patients was noted to be erratic and led largely to inadequate record keeping. This can be reduced by perhaps calling patients whose appointments is due and finding out their reason for not coming for review or for choosing another facility for continued care. A larger study with prolonged follow up patients will be more generalizable to the population.

This is therefore also recommended.

\section{Acknowledgement}

First of all, I am grateful to the Almighty God for enabling me to write this research work and submit it for publication. I wish to thank my supervisors Prof. Ronald Wasike, Dr. Miriam Mutebi and Dr. Ahmed Komen, whose scholarly advice, help and constant encouragement have contributed significantly to the completion of this study. SI also wish to thank the management, staff, faculty members and my fellow residents for their invaluable input and for being a great source of support to me during my study. I am appreciative of the services of Dr. Stanley Aruyaru and Mr. James Orwa who assisted in the proofreading and editing of my paper and to Ms. Carol Mwangi who assisted with formatting and other technical aspects. My gratitude to the library staff especially Mr. George Mwangi and Mr. Sabath Kivuva for their support. Lastly, I am grateful to my lovely wife Rebecca and our son Nathan for their immense support towards achieving this goal.

\section{References}

1. Ferlay J, Shin HR, Bray F, Forman D, Mathers C, et al. (2010) Estimates of worldwide burden of cancer in 2008: GLOBOCAN 2008. International journal of cancer 127(12): 2893-2917.

2. Ginsburg $O$ (2013) Breast and cervical cancer control in low and middle-income countries: human rights meet sound health policy. Journal of Cancer Policy 1(3-4): 35-41.

3. Ferlay J, Soerjomataram I, Dikshit R, Eser S, Mathers C, et al. (2012) Cancer incidence and mortality worldwide: sources, methods and major patterns in GLOBOCAN 2012. Int J Cancer 136(5): 359-386.

4. DeSantis C, Siegel R, Jemal A (2013) Breast cancer facts and figures 2013-2014. American Cancer Society 2013: 1-38.

5. Parkin DM, Bray F, Ferlay J, Pisani P (2005) Global cancer statistics, 2002. CA Cancer J Clin 55(2): 74-108.

6. Mathers CD, Ma Fat D, Inoue M, Rao C, Lopez AD, et al. (2005) Counting the dead and what they died from: An assessment of the global status of cause of death data. Bull World Health Organ 83(3): 171-177.

7. Amend K, Hicks D, Ambrosone CB (2006) Breast cancer in African-American women: Differences in tumor biology from European-American women. Cancer Res 66(17): 8327-8330. 
8. Li CI, Malone KE, Daling JR (2003) Differences in breast cancer stage, treatment and survival by race and ethnicity. Arch of intern med 163(1): 49-56.

9. O'Malley CD, Le GM, Glaser SL, Shema SJ, West DW, et al. (2003) Socioeconomic status and breast carcinoma survival in four racial/ethnic groups. Cancer 97(5): 1303-1311.

10. Chen VW, Correa P, Kurman RJ, Wu XC, Eley JW, et al. (1994) Histological characteristics of breast carcinoma in blacks and whites. Cancer Epidemiol and Prev 3(2): 127-135.

11. Cunningham JE, Butler WM (2004) Racial disparities in female breast cancer in South Carolina: Clinical evidence for a biological basis. Breast cancer research and treatment 88(2): 161-176.

12. Sprague BL, Trentham Dietz A, Gangnon RE, Ramchandani R, Hampton JM, et al. (2011) Socioeconomic status and survival after an invasive breast cancer diagnosis. Cancer 117(7): 1542-1551.

13. Halpern MT, Bian J, Ward EM, Schrag NM, Chen AY (2007) Insurance status and stage of cancer at diagnosis among women with breast cancer: Cancer 110(2): 403-411.

14. Miller BA, Hankey BF, Thomas TL (2002) Impact of sociodemographic factors, hormone receptor status, and tumor grade on ethnic differences in tumor stage and size for breast cancer in US women. American journal of epidemiology 155(6): 534-545.

15. Yood MU, Johnson CC, Blount A, Abrams J, Wolman E, et al. (1999) Race and differences in breast cancer survival in a managed care population. Journal of the National Cancer Institute 91(17): 1487-1491.

16. Chlebowski RT, Chen Z, Anderson GL, Rohan T, Aragaki A, et al. (2005) Ethnicity and breast cancer: factors influencing differences in incidence and outcome. Journal of the National Cancer Institute 97(6): 439-448.

17. Smith Bindman R, Miglioretti DL, Lurie N, Abraham L, Barbash RB, et al. (2006) Does utilization of screening mammography explain racial and ethnic differences in breast cancer? Annals of internal medicine 144(8): 541-53.

18. Carey LA, Perou CM, Livasy CA, Dressler LG, Cowan D, et al. (2006) Race, breast cancer subtypes, and survival in the Carolina Breast Cancer Study. JAMA 295(21): 2492-2502

19. DeSantis C, Jemal A, Ward E (2010) Disparities in breast cancer prognostic factors by race, insurance status, and education. Cancer Causes and Control 21(9): 1445-1450.

20. Fregene A, Newman LA (2005) Breast cancer in sub-Saharan Africa: How does it relate to breast cancer in African-American women? Cancer 103(8): 1540-1550.

21. Furberg H, Millikan R, Dressler L, Newman B, Geradts J, et al. (2001) Tumor characteristics in African American and white women. Breast cancer research and treatment 68(1): 33-43.

22. Porter PL, Lund MJ, Lin MG, Yuan X, Liff JM, et al. (2004) Racial differences in the expression of cell cycle-regulatory proteins in breast carcinoma. Cancer 100(12): 2533-2542.

23. Eley JW, Hill HA, Chen VW, Austin DF, Wesley MN, et al. (1994) Racial differences in survival from breast cancer: results of the National Cancer Institute Black/White Cancer Survival Study. JAMA 272(12): 947-954.

24. Lewison EF (1953) The surgical treatment of breast cancer: an historical and collective review. Surgery 34(5): 904-953.

25. De Moulin D (2012) A short history of breast cancer: Springer Science \& Business Media.

26. Halsted WS I A (1898) Clinical and Histological study of certain adeno carcinomata of the breast: And a brief consideration of the supraclavicular operation and of the results of operations for cancer of the breast from 1889 to 1898 at the Johns Hopkins Hospital. Annals of Surgery 28(5): 557-576.
27. Patey D (1967) A review of 146 cases of carcinoma of the breast operated on between 1930 and 1943. British journal of cancer 21(2): 260-269.

28. Veronesi U (1977) Conservative treatment of breast cancer: a trial in progress at the Cancer Institute of Milan. World journal of surgery 1(3): 324-326.

29. Veronesi U, Saccozzi R, Del Vecchio M, Banfi A, Clemente C , et al. (1981) Comparing radical mastectomy with quadrantectomy, axillary dissection, and radiotherapy in patients with small cancers of the breast. New England Journal of Medicine 305(1): 6-11.

30. Veronesi U, Cascinelli N, Mariani L, Greco M, Saccozzi R, et al. (2002) Twenty-year follow-up of a randomized study comparing breast-conserving surgery with radical mastectomy for early breast cancer. New England Journal of Medicine 347(16): 1227-1232.

31. Arriagada R, Lê MG, Rochard F, Contesso G (1996) Conservative treatment versus mastectomy in early breast cancer: patterns of failure with 15 years of follow-up data. Journal of Clinical Oncology 14(5): 15581564.

32. Fisher B, Anderson S, Bryant J, Margolese RG, Deutsch M, et al. (2002) Twenty-year follow-up of a randomized trial comparing total mastectomy, lumpectomy, and lumpectomy plus irradiation for the treatment of invasive breast cancer. New England Journal of Medicine 347(16): 12331241.

33. Lichter AS, Lippman ME, Danforth DN, d'Angelo T, Steinberg SM, et al. (1992) Mastectomy versus breast-conserving therapy in the treatment of stage I and II carcinoma of the breast: A randomized trial at the National Cancer Institute. Journal of Clinical Oncology 10(6): 976-983.

34. Litière S, Werutsky G, Fentiman IS, Rutgers E, Christiaens MR, et al. (2012) Breast conserving therapy versus mastectomy for stage I-Il breast cancer: 20-year follow-up of the EORTC 10801 phase 3 randomized trial. The lancet oncology 13(4): 412-419.

35. Blichert Toft M, Nielsen M, Düring M, Møller S, Rank F, et al. (2008) Longterm results of breast conserving surgery vs. mastectomy for early stage invasive breast. 32. cancer: 20-year follow-up of the Danish randomized DBCG-82TM protocol. Acta oncologica 47(4): 672-681.

36. Health NIo (1991) Treatment of early-stage breast cancer. NIH Consensus Conference. JAMA 265: 391-395.

37. Edge SB, Compton CC (2010) The American Joint Committee on Cancer: The $7^{\text {th }}$ edition of the AJCC cancer staging manual and the future of TNM. Annals of surgical oncology 17(6): 1471-1474.

38. Schwartz GF, Veronesi U, Clough KB, Dixon JM, Fentiman IS, et al. (2006) Consensus conference on breast conservation. Journal of the American College of Surgeons 203(2):198-207.

39. Morrow M, White J, Moughan J, Owen J, Pajack T, et al. (2001) Factors predicting the use of breast-conserving therapy in stage I and II breast carcinoma. Journal of Clinical Oncology 19(8): 2254-2262.

40. Othieno Abinya N, Nyabola L, Abwao H, Ndege P (2002) Post-surgical management of patients with breast cancer at Kenyatta National Hospital. East African medical journal 79(3):156-162.

41. Anyanwu SN (2008) Temporal trends in breast cancer presentation in the third world. Journal of Experimental \& Clinical Cancer Research 27(1): 17

42. Amir H, Makwaya C, Mhalu F, Mbonde MP, Schwartz Albiez R, et al. (2001) Breast cancer during the HIV epidemic in an African population. Oncology reports 8(3): 659-661.

43. Edge J, Buccimazza I, Cubasch H, Panieri E (2014) The Challenges of managing breast cancer in the developing world-a perspective from sub-Saharan Africa. SAMJ: South African Medical Journal 104(5): 377379.

44. Anders CK, Carey LA (2009) Biology, metastatic patterns, and treatment of patients with triple-negative breast cancer. Clinical breast cancer 9: 73-81.

Cite this article: George IO Orerah. Two to Nine Year Review of Breast Conservation Therapy (BCT) for Breast Carcinoma: Clinico-Pathological Features and Outcomes in a Single Centre in East Africa. Biomed J Sci \& Tech Res 12(5)-2019. BJSTR. MS.ID.002313. DOI: 10.26717/ 
45. Sayed S, Moloo Z, Wasike R, Bird P, Oigara R, et al. (2014) Is breast cancer from Sub Saharan Africa truly receptor poor? Prevalence of ER/PR/ HER2 in breast cancer from Kenya. The Breast 23(5): 591-596.

46. Abdulrahman GO, Rahman GA (2012) Epidemiology of breast cancer in Europe and Africa. Journal of cancer epidemiology 2012.

47. Maalej M, Frikha H, Ben SS, Daoud J, Bouaouina N, et al. (1999) Breast cancer in Tunisia: clinical and epidemiological study. Bulletin du cancer 86(3): 302-306.

48. Salem AA, Salem MAE, Abbass H (2010) Breast cancer: Surgery at the south egypt cancer institute. Cancers 2(4): 1771-1778.

49. Bhikoo R, Srinivasa S, Yu TC, Moss D, Hill AG, et al. (2011) Systematic review of breast cancer biology in developing countries (part 1): Africa, the Middle East, Eastern Europe, Mexico, the Caribbean and South America. Cancers 3(2): 2358-2381.

50. Abdel Wahab M, Bourque JM, Pynda Y, Iżewska J, Van der Merwe D, et al. (2013) Status of radiotherapy resources in Africa: An International Atomic Energy Agency analysis. The lancet oncology14(4): 168-175.

51. Makanga W, Wasike R, Saidi H (2013) A Profile of Female Breast Cancer Patients in a Kenyan Urban Private Hospital. Annals of African Surg ery $10(1)$.

52. Riogi B, Wasike R (2014) Surgical Margin Status after Breast Conservation Surgery at Aga Khan University Hospital Nairobi. Annals of African Surgery 11(1).

53. Smitt MC, Nowels K, Carlson RW, Jeffrey SS (2003) Predictors of re excision findings and recurrence after breast conservation. International Journal of Radiation Oncology Biology Physics 57(4): 979-985.

54. Ramanah R, Pivot X, Sautiere JL, Maillet R, Riethmuller D, et al. (2008) Predictors of re-excision for positive or close margins in breast-conservation therapy for pT1 tumors. The American Journal of Surgery. 195(6): 770-774.

55. Gupta A, Subhas G, Dubay L, Silapaswan S, Kolachalam, et al. (2010) Review of re-excision for narrow or positive margins of invasive and intraductal carcinoma. The American surgeon 76(7): 731-734.

56. Mabula JB, Mchembe MD, Chalya PL, Giiti G, Chandika AB, et al. (2012) Stage at diagnosis, clinicopathological and treatment patterns of breast cancer at Bugando Medical Centre in north-western Tanzania. Tanzania journal of health research 14(4): 269-279.

57. Tesfamariam A, Gebremichael A, Mufunda J (2013) Breast cancer clinicopathological presentation, gravity and challenges in Eritrea, East Africa: Management practice in a resource-poor setting. SAMJ: South African Medical Journal 103(8): 526-528.

58. Freedman RA, He Y, Winer EP, Keating NL (2009) Trends in racial and age disparities in definitive local therapy of early-stage breast cancer Journal of Clinical Oncology 27(5): 713-719.

59. Schoenfeld DA (1983) Sample-size formula for the proportional-hazards regression model. Biometrics 499-503.

60. Cowles MK (2004) Modelling survival data in medical research. Journal of the American Statistical Association. 99(467): 905-907.

\section{ISSN: 2574-1241}

DOI: $10.26717 / B J S T R .2019 .12 .002313$

George IO Orerah. Biomed J Sci \& Tech Res

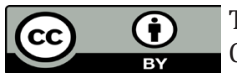

This work is licensed under Creative

Commons Attribution 4.0 License

Submission Link: https://biomedres.us/submit-manuscript.php
61. Ries LA, Harkins D, Krapcho M, Mariotto A, Miller BA, et al. (2006) SEER cancer statistics review: 1975-2003.

62. Tyldesley S, Foroudi F, Barbera L, Boyd C, Schulze K, Walker H, et al. (2003) The appropriate rate of breast conserving surgery: An evidence-based estimate. Clinical Oncology 15(3): 144-55.

63. Yang H, Wang S, Ou W, Sun H, Fang Q (2009) Clinical characteristics and prognosis of very young patients with breast cancer in the southern of China. Chin J Cancer 28(12): 1310-1316.

64. Siegel RL, Miller KD, Jemal A (2018) Cancer statistics, 2018. CA: A cancer journal for clinicians 68(1): 7-30.

65. Anders CK, Johnson R, Litton J, Phillips M, Bleyer A (2009) Breast cancer before age 40 years. Seminars in oncology 36(3): 237-249.

66. Fredholm H, Eaker S, Frisell J, Holmberg L, Fredriksson I, et al. (2009) Breast cancer in young women: Poor survival despite intensive treatment. Plos one 4(11): e7695.

67. Muguti G (1993) Experience with breast cancer in Zimbabwe. Journal of the Royal College of Surgeons of Edinburgh 38(2): 75-78.

68. Parkin D, Vizcaino A, Skinner M, Ndhlovu A (1994) Cancer patterns and risk factors in the African population of southwestern Zimbabwe, 19631977. Cancer Epidemiology and Prevention Biomarkers 3(7): 537-547.

69. Colditz GA, Rosner B (2000) Cumulative risk of breast cancer to age 70 years according to risk factor status: Data from the Nurses' Health Study. American journal of epidemiology 152(10): 950-964.

70. Gakinya S, Sayed S, Chauhan R, Sayed P, Gakinya S (2010) his Breast cancer Molecular subtypes and their clinicopathological characteristics amongst patients at the Aga Khan University Hospital (Nairobi). Annals of African Surgery 5(1).

71. Zarcone M, Amodio R, Campisi I, Cusimano R, Dolcemascolo C, et al. (2009) Application of a new classification to a breast tumor series from a population-based Cancer registry. Annals of the new york academy of sciences 1155(1): 222-226.

72. Nalwoga H, Arnes JB, Wabinga H, Akslen LA (2007) Frequency of the basal-like phenotype in African breast cancer. Apmis 115(12): 1391-1399.

73. Calleb G (2006) Breast Carcinoma at Coast Province General Hospital-Mombasa Kenya. East And Central African Journal of Surgery 11(2): $10-14$.

74. Vorobiof DA, Sitas F, Vorobiof G (2001) Breast cancer incidence in South Africa. Journal of clinical oncology 19(18 SUPP): 125-127.

75. Li C, Uribe D, Daling J (2005) Clinical characteristics of different histologic types of breast cancer. British journal of cancer 93(9): 1046.

76. Smitt MC, Nowels K, Carlson RW, Jeffrey SS (2003) Predictors of re excision findings and recurrence after breast conservation. International Journal of Radiation Oncology Biology Physics 57(4): 979-985.

77. Houssami N, Macaskill P, Marinovich ML, Dixon JM, Irwig L, et al. (2010) Meta-analysis of the impact of surgical margins on local recurrence in women with early-stage invasive breast cancer treated with breast-conserving therapy. European Journal of Cancer 46(18): 3219-32.

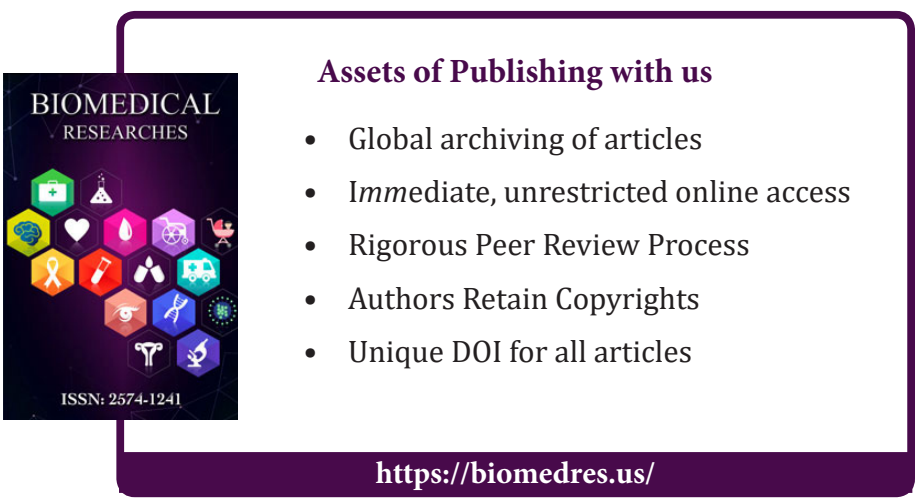

Cite this article: George IO Orerah. Two to Nine Year Review of Breast Conservation Therapy (BCT) for Breast Carcinoma: Clinico-Pathological Features and Outcomes in a Single Centre in East Africa. Biomed J Sci \& Tech Res 12(5)-2019. BJSTR. MS.ID.002313. D0I: 10.26717/ 